\title{
Elements of Architectural Design and Interpretation of Buildings and Monuments in Kaduna State
}

\author{
Isa Sani Mohammed ${ }^{1}$, Anas Muhammad,", Aisha Wali Aminu-Umar ${ }^{3}$ \\ ${ }^{1}$ Department of Civil Engineering, Nigerian Defence Academy (NDA), Kaduna, Kaduna State, Nigeria \\ ${ }^{2}$ Department of Quantity Surveying, Kaduna Polytechnic, Kaduna, Kaduna State, Nigeria \\ ${ }^{3}$ Department of Architecture, Kaduna Polytechnic, Kaduna, Kaduna State, Nigeria
}

Copyright $(\mathrm{O} 2018$ by authors, all rights reserved. Authors agree that this article remains permanently open access under the terms of the Creative Commons Attribution License 4.0 International License

\begin{abstract}
Understanding and interpretation of some features of buildings and monuments at public buildings and utilities is one of the challenges facing end-users and general public particularly the end-users and commuters across the globe. These features shape the final outlook of the buildings and monuments. Therefore, the end-users and commuters understanding on these buildings and monuments should not be ignored at both inception and completion. This is because occupants ought to know how buildings and monuments should look at completion since they will be the end-users. This study assesses elements of architectural design and interpretation of buildings and monuments at public buildings and utilities within Kaduna metropolis which was achieved through; the identification and examination of the principles of architectural intellectual appeal, determination of the current level of understanding and interpretation of buildings and monuments by end-users and general public. A total number of 150 questionnaires were distributed to public buildings and utilities users, commuters and general public within Kaduna metropolis. They were asked to demonstrate their level of understanding in interpreting of buildings and monuments at public places and utilities within Kaduna metropolis. A total of 81 questionnaires were retrieved representing $54 \%$ of valid response rate which were subsequently analyzed using descriptive statistics with the aid of Statistical Package for Social Sciences (SPSS) software. The study found that the level of respondents understanding on the interpretation of buildings and monuments as average. That is attributed to the following reasons: difficulty in understanding and interpretation of some building features and some principles of architectural designs and intellectual appeal as well as lack of using strategies that will enhance the understanding of building features at project inception by designers. Again, partial and complete neglect of end-users by professionals in some projects has made it difficult for them to understanding and interpret buildings and other structures when completed. Lastly, low level of education
\end{abstract}

of some end-users, commuters and general public on elements of architectural design is responsible for their inability to understanding and interpret buildings and other structures.

Keywords Intellectual Appeal, Public Buildings, Monuments, End-users, Commuters and General Public

\section{Introduction}

Buildings and other structures (monuments) are structures that have such architectural or historical significance that have received legal protection. A functional building must comprise the following features: uses, distinctive materials in its construction, was designed by a notable person, was inhabited by a notable person, has a close association with important historical events, is situated within a particular historic environment and is characteristic of a particular area (Art and Humanities Research Council, 2014).

Looking at architecture can be one way to assess the date of a building. Particular materials or features went in and out of fashion over the passage of time, which can provide a good clue as to when a building was constructed or modified. It is also the case that some social groups were associated with particular architectural styles. Architecture sometimes tells us something very important about the people who lived in or used buildings. There are a number of good general guides and resources that can be used to interpret any building or structure which is listed below.

The first step is to consider what strikes you as being distinctive about the building. Are there any features which stand out? Are there any parts of the building in which the architect or builder has shown a little bit of creative flair?

If you are not sure what to look at, then perhaps run through the following questions.

i. What are the walls made out of? 
ii. What does the roof look like?

iii. Are there any windows? If so, how many?

iv. What do the window frames look like?

v. Are there any arches? What do they look like?

vi. Are there any columns?

Source: Pevner (2010)

\section{Monuments}

A monument is a type of structure that was explicitly designed and built to commemorate a person or event, or which has become important to a social group as a part of their remembrance of historic times or cultural heritage, or as an example of historic architecture. The monument is often applied to buildings or structures that are considered examples of Architectural and/or cultural heritage. For example, Burj Khalifa in Dubai, India Gate, Titanic memorial, Belfast, Pyramids of Egypt, Benin Bronze Heads, Ogbunike caves, The Kano city walls, Arometa and Three white cap chiefs (Farlex, 2013).

Cultural Heritage refers to monuments, groups of buildings and sites of heritage value, constituting the historic or built environment. Furthermore, recording is the capture of information which describes the physical configuration, condition and use of monuments, groups of buildings and sites, at points in time, and it is an essential part of the conservation process.

Records of monuments, groups of buildings and sites may include tangible as well as intangible evidence, and constitute a part of the documentation that can contribute to an understanding of the heritage and its related values. (International Council On Monuments and Sites, 1996)

Based on the foregoing, it can be observed that understanding and interpretation of buildings and monuments by end-users and commuters in Nigeria is an important area albeit with some challenges.

\section{Challenges Facing End-Users, Commuters and General Public in Understanding and Interpretation of Buildings and Monuments}

Understanding and interpretation of buildings and monuments at public places and utilities is one of the challenges facing end-users and other commuters across the globe (Davidson, 2003; Pevner, 2010). Elements of architectural designs and some futures shape the final outlook of buildings and monuments (Singh and Singh 2012). So in view of that, end-users, commuters and general publics' understanding of elements of architectural designs and some building features should not be ignored at both inception and completion stages of construction projects. This is because occupants ought to know how buildings and monuments would look like at the completion of projects since they will be the ones to use these structures. Following that, studies have identified and suggested the use of some elements of architectural designs and intellectual appeal, and some building futures
(International Council On Monuments and Sites, 1996; Singh and Singh 2012; Art and Humanities Research Council, 2014).

However, studies have done little in investigating the foregoing in Nigeria, specifically within Kaduna metropolis with a view to determining the current level of understanding and interpretation of buildings and monuments by end-users, commuters and general public as the research population. To this end, this study assesses elements of architectural design and interpretation of buildings and monuments at public places and utilities within Kaduna metropolis which was achieved through, identification and examination of the principles of architectural intellectual appeal, determination of the current level of understanding and interpretation of buildings and monuments by users, commuters and general public in Kaduna metropolis.

\section{Research Questions}

i. What are the principles of architectural intellectual appeal?

ii. What is the current level of understanding and interpretation of buildings and monuments by end-users, commuters and the general public?

\section{Scope}

Respondents (end-users, commuters and general public) were chosen because they are one of the key stakeholders that are really concerned with these buildings and structures within Kaduna metropolis. Furthermore, end-users, commuters and general public are considered because these buildings and structures are meant for them to use for their day to day business.

The issue of logistic limited the number of the questionnaires that were administered. And this is supported statistically since it is possible to represent a population based on a number of samples (Abdullahi, 2014).

\section{Limitations}

The accuracy of the findings determined in this study is limited to the accuracy of data supplied by the respondents in the questionnaire. In general, the research sample was relatively adequate, because it was drawn using a convenient sampling technique which could affect the generalization of the findings.

\section{Literature Review}

\section{Elements of Architectural Design}

Over the ages, man has constructed various types of 
buildings such as palaces, tombs, cottages and places of worship. These buildings and structures reveal many things such as nature of construction, way of life, liking of the people, building materials which were known to them and effects of outsiders who have been invading and ruling the region. To these structures the name Architecture has been given. Architecture has been defined in many ways. Some people have defined Architecture as static and creative art. It may be regarded as the procedure associated with the conception of an idea and its realization in terms of building and Architecture (Art and Humanities Research Council, 2014).

\section{Basis for Development of Architecture}

Fear, love, death and hope, amongst other things, have been the basis for the development of architecture (Singh \& Singh, 2012).

Fear: From primitive times the man has been trying to protect himself from attacks of wild animals and rigorous weather.

Love: Instinct of love gave birth to many monumental works like the Taj Mahal in India.

Death: Death also has been responsible for many architectural constructions. So many historical tombs are examples of these monuments.

Hope: Pyramids and places of worship have come up out of shear false hopes of the man.

These buildings and structures are built based on age long and universally acclaimed principles of intellectual appeal.

\section{Principles of Architectural Intellectual Appeal}

A building right from stage of sketch designs to the stage of its completion needs a programme and organized process. Furthermore, a building is the space organization for utility and is a result of collaboration of various construction materials. The principles of architectural intellectual appeal are:

i. Unity: This means harmony among elements of building which cannot be split from each other. It is that expedient of composition which gives coherence of the parts and integrity of the whole structure

ii. Contrast or Physical appeal: This means absence of monotony. It also deals with creating interest and exhibiting variety. A well-conceived contrast can be in form of size, tone, line and shape. However, if contrast is poorly applied, it may result in multiple divisions of expression and cause serious harm to unity.

iii. Proportion: This is largely a matter of relationship. It is not the actual size but the relative size of one form to another perceivable through comparison which the eye can make between the size, shape, direction and tone of the various elements of composition.

iv. Scale: This means the relation of several parts to one another and to the whole from the aspect of size. Proper scale is not only essential for better result of proportion but it is considered as desirable quality in architecture and as better means toward unity.

v. Balance: This is the equality of mass about axis of reference. There must be balance about axis of reference. On the basis of proper balance in composition harmony and weighed adjustment of different masses can develop and satisfy viewers with reference to relative importance of the various elements of the design. In terms of balance, a building, monument or any other structure can be symmetrical or asymmetrical.

vi. Rhythm: This is the essentially a repetition of pattern. Repeating elements may not be spaced at equal intervals. It is more powerful in appealing to human sense than scale

vii. Character or Expression of purpose: This is referred to as a style. This is the culmination of all such principles in building or structure. In addition to the foregoing, there are other features for examining buildings and other structures.

\section{Features for Examining Buildings and Other Structures}

Table 2.1. Features for examining buildings and other structures

\begin{tabular}{|c|c|}
\hline Doors & $\begin{array}{l}\text { Is the door at ground level or raised? Is it } \\
\text { flanked by columns, or with a portico } \\
\text { above it? Is the door glazed? }\end{array}$ \\
\hline Windows & $\begin{array}{l}\text { Are the windows glazed? If so, are the } \\
\text { panes large or small? Are there shutters? } \\
\text { Are the window frames made from wood, } \\
\text { plastic or metal? Is the top of the window } \\
\text { square, rounded or arched? Is the window } \\
\text { broken up by any interior features, such as } \\
\text { smaller stone arches? }\end{array}$ \\
\hline Roof & $\begin{array}{l}\text { Is the roof flat, curved or ridge-shaped? Is } \\
\text { it of a simple construction, or does it have } \\
\text { multiple gables? }\end{array}$ \\
\hline Walls & $\begin{array}{l}\text { Stone or brick? Or perhaps timber framed? } \\
\text { Has plaster been applied to improve the } \\
\text { appearance? What is the pattern in the } \\
\text { brick work? Is the stone rough or smooth? }\end{array}$ \\
\hline Ground plan & $\begin{array}{l}\text { Does the ground plan suggest that new } \\
\text { additions have been made? Have you } \\
\text { compared maps and plans from different } \\
\text { dates? Can you think of any reasons why } \\
\text { the ground plan is as it is? }\end{array}$ \\
\hline External decoration & $\begin{array}{l}\text { Are there features on the outside of the } \\
\text { building which don't appear to serve any } \\
\text { particular structural purpose? Is there } \\
\text { plaster which has patterns in it? Or a date } \\
\text { plaque? Does the building have a name? } \\
\text { Are there any patterns in the brick or } \\
\text { stone? }\end{array}$ \\
\hline
\end{tabular}

Source: Pevner's Architectural Glossary (2010); Davidson (2003) 
This depends on the building, but the following set out some features for understanding and interpretation of buildings.

\section{Other Features that Aid Understanding and Interpretation of Buildings}

\section{Building Materials}

It is not just architecture that can tell us something important about the history of buildings. By paying attention to the materials employed in their construction, some important insights into how and why they were built can be seen. For instance, imagine that you are studying an old house. Is it built out of stone or brick? Is the roof thatched, tiled or slated? Where did these materials come from? Why did the builders decide to use them? How unusual was their choice? Answering these questions might help to generate some important insights. Examining buildings can tell something about the structures themselves. But it may also permit to gain insights into the surrounding environment. For instance, if a particular type of stone is often used as a building material in an area, then this might offer an important clue about the local geology. Aside the architecture that conveys something important about history, the following are other features that aid understanding and interpretation of buildings and monuments: brick and stone work, brickwork bonds, roof materials, pantiles, glass, metalwork, gravestones, monuments and war memorials. This is because they communicate supplementary information on sole intended purpose of building structures and monuments which cannot be conveyed by mere architecture (Art and Humanities Research Council, 2014).

\section{Summary}

In general, most of the literature reviewed in this study focus attention on identifying elements of architectural design and interpretation, principles of Architectural intellectual, features used in examining buildings and other structures and guidelines that help the understanding and interpretation of buildings and other structures.

\section{Gap/Outstanding issue}

Understanding and interpretation of buildings and monuments at public places and utilities is one of the challenges facing end-users, other commuters and general public across the globe. Following that, studies have been carried on elements of Architectural design and interpretation, principles of Architectural intellectual, features for examining buildings and other structures, and guidelines enhancing the understanding and interpretation of buildings and other structures. However, literature has never investigated this challenge facing end-users in Nigeria, particularly within Kaduna metropolis.

\section{Methodology}

\section{Research Approach}

A quantitative research approach was employed using questionnaire survey for this study. Quantitative research deals with the collection and analysis of data in numeric form or nature (Hughes, 2006). The questionnaire survey helped in getting the needed data for the purpose of actualizing the research objectives by evaluating the data using suitable statistical analytical tools.

Fellows and Liu (1999) stated that quantitative research approach is suitable for collecting data and in examining relationships between facts and help in linking those facts with theories and findings of any research carried out. It deals with measurable and quantifiable issues under research. Furthermore, it also deals with aspects for the measurement of quantity and amount (Eboh, 2009). Quantitative research approaches used scientific techniques to obtain measurements (quantified data) from social surveys such as; questionnaires, interview surveys, telephone survey etc. Lastly, reason of adopting quantitative research approach was to help in achieving the research objectives.

\section{Data Collection Method}

In order to achieve the aim of this research, data was collected via the following:

\section{Literature review}

The research first started with the review of relevant literature. Specifically, extensive literature review of elements of architectural design and interpretation, principles of architectural intellectual appeal, features used in examining buildings and other structures and guidelines that help the understanding and interpretation of buildings and other structures. The principles of architectural intellectual appeal (i.e. unity, contrast, proportion, scale, balance, rhythm and character). This was done purposely to compile the list of principles established around the globe. The review focused on primary sources of data such as journal articles and conference papers. Based on the literature reviewed, lists of seven (7) principles were found to be important in enhancing the understanding and interpretation of buildings and other structures (Singh and Singh, 2012). The principles of architectural intellectual (i.e. unity, contrast, proportion, scale, balance rhythm and character) compiled were used to design a structured questionnaire used to collect data from the field.

\section{Questionnaire survey}

The principles of architectural intellectual appeal, viz: unity, contrast, proportion, scale, balance rhythm and character identified were used to construct a structured questionnaire used for field survey. The questionnaire 
survey assessed the level of criticality of the project success factors identified in literature. Naom (1998), Enshassi et al. (2010) stated that the questionnaire is a widely used approach for descriptive and analytical surveys to find out the facts, opinions and views of respondents. Questionnaires are structured in a precise and concise way in order to avoid ambiguity and checked for expression. Another reason for chosen questionnaire survey is because it offers researchers the opportunity to reach a large number of potential respondents in different locations (Russell, 2006). In general, questionnaire survey helps in collecting information on facts, activities, level of knowledge, opinions, expectations and aspirations, membership of various groups, and attitudes and perceptions relevant to the study (Siniscalco and Auriat, 1998).

As the aim of the research was to "assess elements of architectural design and interpretation of buildings and monuments at public places and utilities within Kaduna metropolis", the focus of the questionnaire survey was to establish the current level of understanding and interpretation of buildings and monuments by users, commuters and general public in Kaduna metropolis.

The questionnaire comprised of two sections (A and B). Section 'A' deals with profile of the respondents such as type/category, experience and qualification. This background information helps in ascertaining the reliability and credibility of data from the survey. Section (B) deals with ratings of the current level of understanding and interpretation of buildings and monuments by users, commuters and general public in Kaduna metropolis. Based on the ratings for the level of understanding and interpretation of buildings and monuments by users, commuters and general public in Kaduna metropolis of those principles, Likert rating scale was employed. Likert scale was employed because it generally includes an equal number of positively and negatively phrased statements.

The principles of Architectural intellectual (i.e. unity, contrast, proportion, scale, balance rhythm and character) were rated based on level of understanding of respondents (end-users, commuters and general public) on a five (5) points likert rating scale of 1 to 5,1 being too low and 5 being very high where;

$$
\begin{aligned}
& 1=\text { too low } \\
& 2=\text { low } \\
& 3=\text { average } \\
& 4=\text { high } \\
& 5=\text { very high }
\end{aligned}
$$

\section{Population of the Study}

A finite population is a collection of a known number of identifiable units. In this case, the known number is called the population size. The population of this study consists of three categories of respondents; end-users, commuters and general public. Samples were drawn from the target population to get the desired information to evaluate the elements of architectural design and interpretation of buildings and monuments at public places and utilities within Kaduna metropolis.

\section{Sample}

Inferences about the population can be made on the basis of a properly designed and well selected sample. A sample is a fraction or a subset of the population. Samples are usually drawn with the aim of estimating the population parameters. Sampling is the act of drawing samples from the population; it essentially saves time and cost. Usually some units are selected from the entire units of the population. In this case, the selected units are called the sample size. Moreover, in this research, samples were drawn from the target population based on a statistically determined, efficient sample size so as to estimate some parameters of the population. The estimated population quantities were then used to evaluate the elements of architectural design and interpretation of buildings and monuments at public places and utilities within Kaduna metropolis.

\section{Sample Size}

The determination of sample size is a common task for many empirical researchers. Inappropriate, inadequate, or excessive sample sizes continue to influence the quality and accuracy of research. A formula for selecting the sample size for a research problem based on a level of significance and a chosen margin of error was proposed by Cochran (1977) and Levy and Lemeshow (2008). In order to obtain the most efficient, representative sample, for our research, we use the following Cochran's formula for sample size determination.

$$
n=\left(\frac{Z_{\alpha / 2}}{2 \delta}\right)^{2}
$$

Where;

$\mathrm{n}=$ Sample size to be determined

$\delta=0.08$ (The chosen margin of error for the survey)

The value of the standard normal ordinate at $\alpha \%$ level of significance is $Z_{\alpha / 2}$. At the $5 \%$ level of significance $Z_{\alpha / 2}=Z_{0.025}=1.96$. The sample size is finally determined as follows.

$$
n=\left(\frac{Z_{\alpha / 2}}{2 \delta}\right)^{2}=\left(\frac{1.96}{2 \times 0.08}\right)^{2}=150
$$

That is, we need a sample size of at least 150 to arrive at a sample with a sampling error of at most $8 \%$.

\section{Stratified Random Sampling}

Since the total number of targeted respondents for this 
study is not known, a survey sampling was used. In survey sampling, it may be desirable or even necessary to divide the population into several subpopulations or strata in order to estimate population parameters. In stratified random sampling, the population units are divided into a number of strata. Samples of predetermined sizes are drawn independently from each stratum by simple random sampling.

In this research work, the necessity of stratification is due to administrative convenience, field operations and increase in precision of survey results. Thus for administrative convenience, three categories of respondents: end-users, commuters and the general public are each treated as a stratum. Then to assess elements of architectural design and interpretation of buildings and monuments at public places and utilities within Kaduna metropolis, we select samples from each stratum. Since a stratified sample consists of units selected separately from each stratum, such a sample is expected to be better representation of the population than a simple random sample selected from the entire population (Levy and Lemeshow, 2008). The following table summarizes the sample size allocation in this stratified random sampling:

Table 3.1. Sample sizes in each stratum

\begin{tabular}{|c|c|}
\hline $\begin{array}{c}\text { Strata (Type of } \\
\text { Respondents) }\end{array}$ & Sample size \\
\hline End users & 50 \\
\hline Commuters & 50 \\
\hline General public & 50 \\
\hline Total & 150 \\
\hline
\end{tabular}

\section{Sampling Strategy}

An effective strategy reduced non response, response error and respondents' bias to the barest minimum. In this strategy, the questionnaires not returned or not properly filled are replaced with new ones in order to maintain an effective sample size of 150 . This is a strategy of minimizing non response. This is because a respondent must respond to all the questions in the questionnaires for his response to be validly analyzed. An effective sample size of at least 150 must also be maintained in order to control the sampling variability. In the data collection process, non-response could be minimized with adequate follow-up as much as possible. In spite of the follow-up, some non-response cases might still be recorded which could only be overcome by extending the sample size sequentially until the desired number of respondents was covered.

\section{Questionnaire}

A total of 150 questionnaires were administered to respondents (end-users, commuters and the general public) at public buildings and utilities within Kaduna. Some public buildings and utilities within Kaduna metropolis were considered because they serve as platform for easy access to most of the respondents as it was not possible to cover the whole of Nigeria in the study. It is possible to use the most representative sample size in research to get a valid and reliable result that can be generalized in the universe (Abdullahi, 2014). Out of the 150 questionnaire distributed, eighty-one (81) were completed and returned representing 54\% valid response rate. Data collected were analyzed using descriptive analytical tool with the aid of Soft Package for Social Sciences (SPSS).

\section{Data Presentation and Analysis}

The data obtained from the questionnaire survey were presented using frequencies and percentages.

\section{Descriptive Statistics}

Weighted means and standard deviations were used in rating the current level of understanding and interpretation of buildings and monuments by users, commuters and general public in Kaduna metropolis.

\section{Data Presentation}

\section{Survey on Respondents' Status}

The responses from the survey are as follows: thirty-seven (37) formed the responses from end-users; twenty-six (26) formed the responses from commuters, and eighteen (18) form responses from the general public. The response can be presented in the following percentages: end-users formed $45.68 \%$, commuters formed $32.09 \%$ and the general public formed $22.23 \%$. The distribution of data collection by respondents' status shows that there was wider coverage in capturing respondents' views and opinions.

\section{Survey on Respondents' Qualifications}

The data collection on qualification shows that the respondents with Senior Secondary Examination Certificate form 20.88\%, National Diploma (ND) form $18.3 \%$ and Higher National Diploma (HND) form $17.16 \%$. Respondents with Bachelor of Science (BSc) form 23.56\%, respondents with Master of Science (MSc) form 16.98\% and respondents with Doctor of Philosophy $(\mathrm{PhD})$ form $3.12 \%$. That shows majority of the respondents have reasonably educated. Based on that, it can be concluded that majority of the respondents are educated. That would further authenticate the reliability and validity of data obtained from the survey.

\section{Survey on Respondents' Years of Familiarization with Buildings/Structures}

The distribution of data collection by respondents' years 
of familiarization with buildings/structures shows that respondents with 5-10years form $20.33 \%, 11-15$ years form $34.33 \%, 16-20$ years form $25.00 \%$ and above 20 years form $20.34 \%$. That has shown majority of the respondents are familiar with the buildings and structured surveyed in this study. That has also helped the validity and reliability of data obtained in this study.

The following are some additional comments/ suggestions made by the respondents:

- Most of the respondents easily interpreted the design concepts of round-abouts.

- Monuments are easier to interpret compared to buildings.

- Designers need to develop strategies that will make enhance the understanding of building features at project inception.

- Partial and complete neglect of end-users by professionals in some projects has made it difficult for them to understanding and interpret buildings and other structures when completed.

- Low level of knowledge of some end-users, commuters and general public on elements of architectural design and intellectual appeal is responsible for their inability in understanding and interpretation of some features in buildings and other structures.

\section{Data Analysis}

\section{Assessment of Weighted Means and Standard Deviation (SD) on the Current Level of Understanding and Interpretation of Buildings and Monuments by Respondents within Kaduna Metropolis}

The rating made by respondents on their current level of understanding and interpretation of buildings and monuments are in descending order. The results are as follows: unity, contrast, proportion, scale, balance, rhythm and character. In general, the results show that the current level of understanding and interpretation of buildings and monuments of Kaduna metropolis as "average". This is because most of the ratings on the level of current level of understanding and interpretation of buildings and monuments are made within the range of 2.51-3.23.

The standard deviation values calculated for these principles are below 1.00: unity, contrast, proportion, scale, balance and character. The low standard deviation values obtained which are below 1.00 for principles show that the ranking were made clustered around the mean values. That signifies the respondents ranking on those set of tools/ways is consistent. That shows a kind of agreement on the respondents ranking. But the highest standard deviation values obtained for this principle which is above 1.00 on rhythm show that the respondents have a disagreement on that. This is because the overall respondents' ranking on their current level of understanding and interpretation of buildings and monuments within Kaduna metropolis was not made clustered around the mean values.

Table 4.1. Weighted Means and SD on the current level of understanding and interpretation of buildings and monuments within Kaduna metropolis

\begin{tabular}{|c|c|c|c|}
\hline Principles & Mean & Standard deviation & Rank \\
\hline Unity & 3.23 & 0.127893 & 1 \\
\hline Contrast & 3.19 & 0.534110 & 2 \\
\hline Proportion & 3.06 & 0.109024 & 3 \\
\hline Scale & 2.87 & 0.412589 & 4 \\
\hline Balance & 2.63 & 0.890001 & 5 \\
\hline Rhythm & 2.59 & 1.018845 & 6 \\
\hline Character & 2.51 & 0.607890 & 7 \\
\hline
\end{tabular}

Very High $(\mathrm{VH})=(4.5-5)$, High, $(\mathrm{H})=(3.5-4.4)$, Average $(\mathrm{A})=$ $(2.55-3.49), \operatorname{Low}(\mathrm{L})=(1.5-2.49)$, To Low $(\mathrm{TL})=(0.00-1.49)$

Source: Field work 2017

\section{Discussion of Findings}

The results show that, the current level of understanding and interpretation of buildings and monuments as average. This is because most of ranking made by the respondents (end-users, commuters and general public) on their current level of understanding and interpretation of buildings and monuments within Kaduna metropolis are within the range of 2.55-3.49. This range falls within the average ratings as highlighted in table 4.1. The results conform to assertions made by Davidson (2003); Pevner (2010); Singh and Singh (2012) who believed that enhancing stakeholders understanding and interpretation of some buildings features and element of architectural designs and intellectual appeal is an area that requires effort. This effort is aimed at using these principles and tools toward enhancing stakeholders understanding and interpretation of buildings and other structures. Based on the results obtained, it can be observed that the key stakeholders considered were not adequately engaged at the projects inception of these buildings and structures surveyed in this study. This is because the overall results obtained for their understanding of those principles is average. The respondents' disagreement in their ranking on this principle (rhythm) may be linked to their perception and divergent views because of their status and interest in this area.

\section{Conclusions}

It was found that the current level of understanding and interpretation of buildings and monuments as average. This is attributed to the following reasons pointed out in the study: difficulty in understanding and interpretation of some building features and elements of architectural designs and intellectual appeal, lack of using strategies that will enhance the understanding of building features at project inception. Again, partial and complete neglect of 
end-users by professionals in some projects have made it difficult for them to understanding and interpret buildings and other structures when completed. Lastly, low level of knowledge of some end-users, commuters and the general public on the principles of intellectual appeal is responsible for their inability to fully understand and interpret buildings and other structures.

\section{Recommendations}

In view of the findings of this research work, there is the need for adequate engagement of end users at project inception stage with a view to enhancing their understanding and interpretations on principles of intellectual appeal of buildings and other structure.

\section{Recommended Areas for Further Studies}

i. Subsequent research work in this subject area should determine more principles and tools that will enhance the understanding and interpretation of buildings and monuments.

ii. Since the current level of end-users understanding and interpretation of buildings and monuments is average, attention should be focused more on how to further enhancing their understanding of projects before they commence.

iii. Designers should try as much as possible to adequately engage end-users and other key stakeholders of buildings and other structure projects at inception stage.

iv. Specific institutions, organizations and neighborhoods in Kaduna should be studied to validate the buildings.

\section{REFERENCES}

[1] Abdullahi, M. (2014). Assessing contractors' cash flow forecasting process capability in Nigeria an unpublished MSc dissertation submitted to the department of Quantity Surveying, Ahmadu Bello University Zaria, Nigeria.

[2] Art and Humanities Research Council (2014). Interpreting buildings and monuments a guide for community history and heritage groups, School of History, University of Leicester, UK.
[3] Cheung, K.C, Mooi, L.C. (1994). A Comparison between the rating scale model and dual scaling for Likert scales.

[4] Cole, J.Y and Reed, H.H (1997). The library congress: The Art and Architecture of the Thomas Jefferson Building. Norton pp. 16 ISBN 978-0-393-04563-5.

[5] Cochran J.K (1997). Organizational research for determining appropriate sample size in survey Research. Wiley online. https://www.wiley.com> en-us.

[6] Davidson, C. C (2003). How to Read Buildings: A Crash Course in Architecture (Herbert Press).

[7] Eboh, E.C. (2009). Social and Economic Research principles and methods. African institute for applied economics, Enugu, Nigeria.

[8] Enshassi. A, Mohammed S. and El-Karriri, A. (2010) Factors Affecting the Bid/ No. Bid Decision in the Palestinian Construction Industry. Financial, Management Construction Journal 15 (2).

[9] Fellows, R and Liu, A (1999). Research Methods for Construction. Blackwell Science Ltd.

[10] Field, A. (2005). Discovering statistics using SPSS for windows, sage publications, London.

[11] Hughes, C.L. (2004). Quantitative and qualitative approaches. Department of Sociology University of Warwick, CV4 7AL United Kingdom.

[12] Ibrahim, M.L. (2014). Appraisal of Stakeholders Management Practice in TETFUND. An unpublished MSc Dissertation Department of Quantity Surveying, Ahmadu Bello University, Zaria, Nigeria.

[13] International Council on Monuments and Sites (1996). Principles for the recording of monuments, groups of buildings and sites.

[14] Levy, P and Lemeshow, S (2008). Sampling of populations: methods and applications. $4^{\text {th }}$ edition. Wiley series in survey methodology. ISBN: https://www.wiley.com> en-us. 978-0-470-04007-2.

[15] Mark, P (1993). Statements in stone: Monuments and society in Neolithic Brittany. Routledge, London. ISBN. 0415067294. Pp. 1-7.

[16] Naoum S.G (1998). Dissertation Research and Writing for Construction Students. Read Education and Professional. Oxford; 23 (9) 38-48.

[17] Pevner (2010). Architectural Glossary. Yale University Press.

[18] Singh, G. and Singh, J. (2012). Building Planning, Design and Scheduling. Published by N.C. Jain Standard Publishers Distributors. 1705-B, Nai Sarak, Delhi 110006.

[19] Thefreedictionary.com. the free dictionary by Farlex retrieved 2013-10-23 